EPOS, XIII (1997), págs. 371-378

\title{
NUEVAS VERSIONES
}

JosÉ Fradejas Lebrero

UNED

\section{TRES VERSIONES MÁS DE GRISELIDES}

El resumen bibliográfico de Rafael Morabito ${ }^{1}$ enumera dieciséis versiones hispánicas, o en «spagnolo». De las cuales se dan, como citadas por primera vez por mí, tres: la de Pérez de Moya, y las dos folklóricas de Asturias y de Puerto Rico ${ }^{2}$. Hoy podemos añadir tres más: una del siglo XVII (1603), otra del s. XVIII y, aún más, otra del s. XX.

La primera se halla en la obra Defensa de las damas, incluida en La Miscelánea austral, Lima, 1602, de Diego de Ávalos y Figueroa. Son siete octavas reales del Canto II, fols. $24_{R}-26_{R}$.

46. Bien descuidada de mudar estado y la suerte, que el cielo le mejora, repastaba Griselda su ganado, contento con tenerla de pastora;

' MORABITO, RAFAel (1989): «La diffusione de la Storia di Griselda dal XIV al XX sécolo», Studi sul Boccaccio, XVII, pp. 269-271.

2 Fradejas, José (1985): Novela corta del S. XVI, Barcelona, Plaza y Janés, 2 vols., T.I., pp. 210 y T. II., pp. $790-800$. 
cuando el sabio Gualtero enamorado la collocó a Marqueza y gran señora de Saluzia, haziéndola su esposa, por su fama en virtud, y en ser hermosa.

47. Con modestia goza de esta gloria, de este summo valor, $y$ beneficio, que jamás despreció de su memoria su nascimiento, y pastoral oficio: y por saber el fin de esta victoria, que era de un claro ser notable indicio, usó el Marqués de un toque y una prueba para ver los quilates con que aprueba.

48. Fingió tener espresso mandamiento del gran vicario, y de los suyos ruego, para que dirimiesse el sacramento que los ligaba, y se cassase luego. Ella con rostro lleno de contento, y el triste coraçón de rabia y fuego responde: como nunca amé la vida nunca de mi la muerte fue temida.

49. Siempre juzgué mi bien ser accidente, $y$ mi thesoro en sueño imaginado, y bien paresce assí por lo presente, pues en vida sin culpa me ha faltado no merescerlo, causa es suficiente, (fuerça que siempre me caus 6 cuidado) porque en el trono inmerito, es indicio que ha de parar en grande precipicio.

50. Contentad vuestro gusto señor mío, tomad en hora buena dulce esposa, con quien os ruego que os mostréis mas pío que con Griselda, solo en vos dichosa. Luego se puso el traje, con que el frío sufrio en el campo, y fiesta rigurosa; y se bolvió a cuidar de su ganado, exercicio en su mente aun no borrado. 
51.

Viendo el Marqués tan singular firmeza,

y su paciencia ya tan confirmada,

$y$ en humildad tan sin igual fineza,

en tiempo que pudiera estar quebrada;

publicando su estremo, y su riqueza

la rescibe, y le muestra cuán preciada

es de su amor, y su conoscimiento,

con que vino en los dos a más aumento.

52.

Aquí verá quien de razón caresce, y podrá conoscer quien verdad ama

la estimación, que un hecho tal meresce, y con cuanta razón canta la fama; y debe ponderar cuanto floresce

la contra de altivez en esta dama; mostrando bien assí, que el que se humilla, en lo supremo pone assiento y silla.

Es un escueto resumen; ya que no se menciona el nacimiento y secuestro de los hijos, y se limita a enviarla a su casa y recibir luego a Griselides de nuevo.

La segunda versión se encuentra en un libro muy difundido durante los siglos XVIII y XIX, en los que se publicaron por los menos diez ediciones. Su autor es el francisco Juan Laguna y la obra los Casos raros de vicios y virtudes para escarmiento de pecadores y ejemplo de virtuosos, Barcelona, A. Arroque (1745) (aunque yo utilizo la edición de Murcia, Phelipe Teruel, 1763), Cap. I: «De la obediencia que deben tener las mugeres casadas», fols. 2-21. Es una demorada, novelesca y moralizante narración con el título de La más humilde princesa. Su fuente es Petrarca, indirectamente, pues el P. Laguna dice:

Refiere Petrarcha, citado por Engelgrave en el Sermón de la Conversión de San Pablo (fol. 2).

y lo repite al final, nuevamente:

esta estoria, que trae Engelgrave en el lugar citado

justificando así el valor moralizante de la novelita:

He escrito aquí, no para que los maridos hagan semejantes experiencias con sus mugeres, sino para que las mugeres con este exemplo 
aprendan como deben estar obedientes a sus maridos; pues si esta, en cosas tan arduas estuvo tan humilde, y pronta para obedecer, cuanto más bien deben obedecer a sus maridos las mugeres, en cosas que les mandan mucho menores? Ya sea en la condición de el marido; ya sea en el menoscabo de los bienes de fortuna; ya sea en orden a sus hijos; en todo deben estar conformes (fol. 21).

La tercera versión es indirecta, ya que es la traducción de El drama de Griselda en rimas y por personajes, obrita francesa escrita en 1395, que ha traducido y publicado Josefa López Alcaraz en Murcia, 1988.

En España se encuentran versiones de los siglos XIV al XVIII y XX; hay, sin embargo, un siglo en blanco, el XIX, que quizá pueda llenarse recordando las versiones populares de Puerto Rico y Asturias.

Versión popular

Boccacio

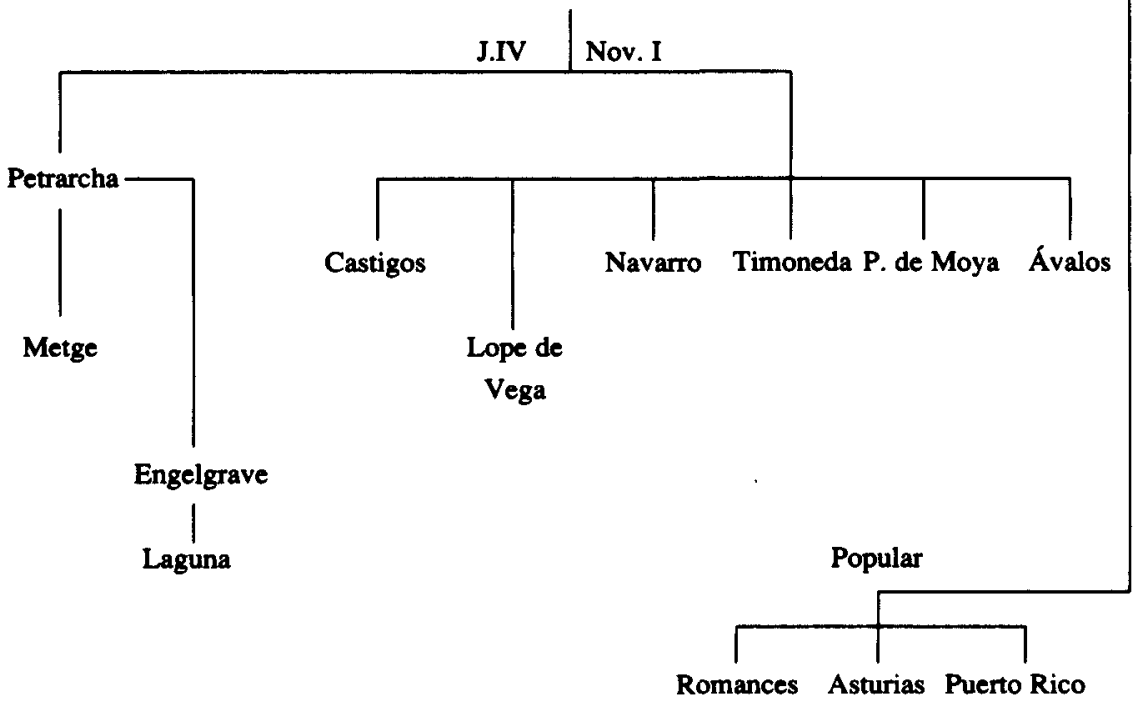




\section{CuATRo versiones MÁs DE PONER EL CASCABEL aL GATO}

En el Homenaje que la Universidad Complutense dedicó a mi buen amigo y Decano Francisco Sánchez Castañer en 1981, contribuí con un pequeño estudio titulado Evolución hispánica de un cuento puertorriqueño. Me refería al cuento-fábula ¿Quién le pone el cascabel al gato ${ }^{3}$ que, según Thompson, es el motivo J $671.1^{4} \mathrm{y}$, según Aarne-Thompson, se le adscribe el tipo núm. $110^{5}$.

Nuevas lecturas me han deparado una versión $\longrightarrow$ dos, según se miredel S. XVI y otras dos de los S. XVIII del S. XIX. Con ellas llenamos la laguna entre Sánchez de Vercial (S. XV) y Felipe Mey (S. XVII) por un lado. Francisco Guzmán publicó unos Triumphos morales en Alcalá en 1565, en cuyo Triumpho de la Fortaleza, fol. 121, incluye estas dos octavas reales:

Entraron en consejo los ratones por ver de qué manera bivirfan, seguros de las malas intenciones del gato de quien siempre se temían. Después de dadas todas sus razones, concluyen, pues matarle no podian, que cierta campanilla le pusiessen a fin de que desde lexos lo sintiessen.

Pues este buen acuerdo ya tomado, queriendo que por obra se pusiesse, no fue ninguno dellos tan osado que cargo del echársela quisiesse. Sería gran varón cualquier letrado si bien como lo dize lo hiziesse, mas ay en conclusión del dicho al hecho según común proverbio, gran trecho.

Treinta y cinco años más tarde, Diego Gutiérrez Salinas public6 - también el Alcalá, 1600- los Discursos del pan y el vino del Niño Jesús, en cuyo Libro II, Capítulo XVIII, fol. 106v-107, nos ofrece esta versión dependiente de la de Guzmán:

${ }^{3}$ Anales de Literatura Hispano-Americana (1981), vol. IX, núm. 10, pp. 85-97.

4hompson, STTTH (1955-1956): Motif-Index of Folk-Literature, Blomington, Indiana University Press.

S AARNE, DUTTI y Thompson, STTTH (1964): The Types of the Folklore, Helsinki, FF Communications, núm. 184. 
El verso quinto de la primera octava ofrece una sola variante, frente a concluyen, pues matarle no podían

Gutiérrez Salinas dice

acuerdan, pues matarle no podían.

Pero donde la acción o intención de originalidad se muestra es en la segunda estrofa, bien que en el verso primero dirá Gutiérrez Salinas:

aviendo este consejo ya tomado

y en el tercero sustituirá el verbo fue por ubo y en el cuarto propone el hiato de-echársela, frente al artículo contracto del. Pero donde se muestra totalmente original es en la moraleja o postfabulación, ya que dice:

Los hombres deste mundo han procurado

vivir de su trabajo y intereses,

pero en llegando al premio del dinero

no hay hombre que no sea peor que un Nero.

Lo cual no acredita a Gutiérrez Salinas de metrificador.

Tras Samaniego, amigo y admirador, aparece el también vasco Josef Agustín Ibánez de la Rentería, cuyas Fábulas en verso castellano de 1789, incluye una revisión, quizá por más vulgar en su versificación, casi desconocida. Hela aquí:

El concejo de los ratones
A los ratones, daba Miauregato, enemigo mortal de su pellejo, tan inhumano trato, que fue preciso convocar concejo para tomar medidas las que quedaban de salvar sus vidas.

Eran los pareceres diferentes:

algunos más prudentes, conociendo del riesgo la importancia decían se dexase aquella estancia: a otros atolondrados detenía el amor a los bocados. 
En esto un ratoncillo presumido

dixo: Yo he discurrido

modo con que a lo menos por sorpresa

no ha de lograr en adelante presa

el medio es muy barato,

no hay más que echar un cascabel al gato.

Oyóse la propuesta, y sin examen

siguió todo el congreso su dictamen:

Execútese, claman al momento.

¿Y a quién se ha de encargar? Aquí fue el cuento:

Toditos se excusaron uno a uno,

y en conclusión no se atrevió ninguno.

¿Dónde está, pues, el que hizo la propuesta?

marchóse a discurrir otra como ésta.

En un Ayuntamiento

se verán más de ciento,

que son en las propuestas elocuentes;

pero en la execución poco valientes.

(Libro I. Fábula XVI, pp. 22-23).

Otra laguna, la del siglo XIX, entre Ibáñez y las versiones americanas de White-Lea y Camino nos los suministra Francisco Alvarado del O.P (El Filósofo Rancio) en sus Cartas críticas que escribio el R.P. Maestro ... en Madrid, Imprenta de E. Aguado, 1824-1823, 4 vols. En el volumen IV, pp. 298-299 nos ofrece una versión interesantísima, pues nos da una versión política cien años antes de lo que suponíamos por la versión de Marcelino Canino en Yabucoa. que nos sorprendió en aquel entonces:

Tenía un gato tan acosados a los ratones, que no podían salir del agujero sin exponerse a no volver jamás. Los ratones, a quienes por una parte urgía la hambre, y por otra amedrentaba el gato, juntaron consejo para ocurrir a un mal tamaño.

Propuso el decano, hablaron casi todos, discutieron los más respetables vocales, y la resolución que de común acuerdo se tomó fue que al gato se le pusiese un cascabel, para que a proporción de lo lejos o cerca que éste sonase, se pudiera entender si amenazaba mucho el peligro.

- Conclamatum est, murmullo de aprobación (y ya iba a levantarse la sesión). 
Pero un ratón sin pelo de barba, que era el más moderno de la asamblea, suplico a los padres conscriptos una sola palabrita para exponer cierto escrupulillo que le quedaba. Se le concedio la palabra; y después de haber alabado la sabiduría de la determinación, dijo: que aún no estaba concluido el asunto; pues faltaba señalar la comisión que debería poner el cascabel al gato.

Se inician aquí, con la comisión, el sentido político que muestra en plenitud la versión recogida, en décimas, por M. Canino en Yabucoa. 